\title{
ESPAGNE, Michel, Le paradigme de l'étranger. Les chaires de littérature étrangère au XIXe siècle
}

Christophe Duhamelle et Patrice Veit

\section{OpenEdition}

\section{Journals}

Édition électronique

URL : http://journals.openedition.org/ifha/2053

DOI : $10.4000 /$ ifha. 2053

ISSN : 2198-8943

Éditeur

IFRA - Institut franco-allemand (sciences historiques et sociales)

Référence électronique

Christophe Duhamelle et Patrice Veit, «ESPAGNE, Michel, Le paradigme de l'étranger. Les chaires de littérature étrangère au XIXe siècle », Revue de l'IFHA [En ligne], Date de recension, mis en ligne le 01 janvier 1994, consulté le 22 septembre 2020. URL : http://journals.openedition.org/ifha/2053 ; DOI https://doi.org/10.4000/ifha.2053

Ce document a été généré automatiquement le 22 septembre 2020.

(C)IFHA 


\title{
ESPAGNE, Michel, Le paradigme de l'étranger. Les chaires de littérature étrangère au XIXe siècle
}

\author{
Christophe Duhamelle et Patrice Veit
}

1 Le premier cours de littérature étrangère en France, celui de Claude Fauriel, ne débuta à Paris qu'en décembre 1830. Est-ce à dire qu'on ignorait jusque-là tout des productions littéraires d'autres pays? Cette nouvelle création, que suit assez vite la mise en place du même enseignement dans les universités de province, est plutôt l'indice d'une transition entre une conception universelle de la littérature (un universel pensé comme naturellement dominé par la France) et l'appréhension des " caractères nationaux » à partir des ouvrages de l'esprit. En étudiant les chaires de littérature étrangère, M.E. peut donc reconstituer une facette officielle du prisme au travers duquel l'étranger est vu, en France, aux temps du nationalisme.

2 Cet ouvrage permet de découvrir concrètement - en suivant les professeurs, leur formation, l'orientation de leurs cours, leurs auditoires souvent limités - l'apparition de la nouvelle discipline, qui tend à son tour à se diviser en « spécialités » à la fin du siècle, à mesure que les études germaniques, anglaises, italiennes, slaves, etc. s'individualisent. L'auteur montre ainsi comment, à partir d'analyses philologiques, se développe une nouvelle approche des textes étrangers, non plus sur le seul critère du goût, mais en fonction d'un concept d'identité culturelle fondé sur l'étude des grands textes et sur une division en « domaines » (le Nord, le Sud, les Slaves...).

3 Dans ce procès d'invention de l'étranger, l'Allemagne joue depuis Madame de Staël - un rôle moteur sans que, tant s'en faut, les chaires de littérature étrangère aient l'initiative en ce domaine. Ce sont en effet les instruments d'analyse développés d'abord en Allemagne (philologie, historicisme...) qui, diffusés entre autres par une forte immigration allemande et par les Alsaciens, contribuent à forger la notion d'identité culturelle qui s'exprime dans le nouvel enseignement et rejaillit également sur l'étude de la littérature française ou régionale. Si l'Allemagne devient ainsi le 
paradigme de l'étranger, elle contribue donc aussi à construire, en réaction/imitation, le critère du national.

4 Christophe DUHAMELLE, Patrice VEIT 